\title{
Determination of Antimicrobial Activity of Some Commercial Fruit (Apple, Papaya, Lemon and Strawberry) against Bacteria Causing Urinary Tract Infection
}

\author{
Sabiha Jahan Liya and Romana Siddique* \\ Department of Mathematics and Natural Sciences, BRAC University, 66 Mohakhali, Dhaka-1212, Bangladesh
}

Received: 12 June 2018; accepted: 11 July 2018

\begin{abstract}
Urinary Tract Infection (UTI) is a worldwide phenomenon in modern times, in which the dependency on antibiotics for its treatment is increasing. The current study was conducted in order to find alternatives to antibiotics by investigating some commercial fruits for their antimicrobial activity. The fruits in this study included green apple (Malus domestica), papaya (Carica papaya), lemon (Citrus limon), and strawberry (Fragaria ananassa), which were used to prepare methanolic and ethanolic extracts through Soxhlet extraction technique. The extracts were used against bacteria that cause UTI, and five different strains were selected: E. coli (ATCC: 15922), E. coli (ATCC: 25922), Pseudomonas aeruginosa (ATCC: 27853), Enterococcus faecalis (ATCC: 29212), and Klebsiella pneumoniae. Antimicrobial tests of the extracts were conducted by following the agar well diffusion method, where ciprofloxacin was used as a positive control, and autoclaved distilled water was used as a negative control. Among the fruits, apple and papaya extracts did not show any zone of inhibition against any of the tested bacteria. However, both lemon and strawberry extracts showed inhibition zone against all of the mentioned bacteria. The ethanolic extracts of lemon and strawberry were more potent than their methanolic extracts. Lemon ethanolic extract showed the highest zone of inhibition against Pseudomonas aeruginosa (ATCC: 27853$)(18.34 \pm 0.58)$ and lowest one against Klebsiella pneumoniae $(16.00 \pm 1.00)$. Strawberry ethanolic extracts showed the highest zone of inhibition against Pseudomonas aeruginosa (ATCC: 27853) (16.33 \pm 0.58$)$ and the lowest one against Klebsiella pneumoniae $(13.33 \pm 0.58)$. As antibiotic resistance is paving the way for multidrug resistant bacteria, the results of lemon and strawberry can be considered to be used as an antimicrobial agent in treating urinary tract infections.
\end{abstract}

Keywords: UTI, Soxhlet, methanolic extracts, ethanolic extracts, agar well diffusion

\section{Introduction}

Urinary tract infection (UTI) is the condition where infecting bacteria invade the urethra and bladder and obstruct urine flow by causing inflammation, intolerable pain, and cloudy urine, along with nocturia and haematuria [1]. UTIs are among the most common bacterial infections, affecting 150 million people each year worldwide, causing morbidity in infant boys, old men, and females of all ages [2]. UTIs are caused by both Gram-negative and Gram-positive bacteria, as well as by certain fungi. The most common causative agent for UTIs is uropathogenic Escherichia coli (UPEC), followed in prevalence by Klebsiella pneumoniae, Staphylococcus saprophyticus, Enterococcus faecalis, group B Streptococcus, Proteus mirabilis, Pseudomonas aeruginosa, Staphylococcus aureus, and Candida spp. [2]. Antibiotics such as trimethoprim, sulphamethoxazole, and ciprofloxacin are among the most commonly recommended therapeutics for UTIs [3]. However, the rise of antibiotic resistance and high recurrence rates of such common infections leave a great impact on our society [2]. For centuries, plants have been used around the world as drugs and remedies for various diseases and infections [4].

Apples have been found to have very strong antioxidant activity and antimicrobial properties [5]. Extracts from organically grown apples exhibited a clear antimicrobial activity against Bacillus cereus and E. coli. In this case, their peel was found to possess a discrete activity, where the inhibition zones increased from $6 \mathrm{~mm}$ to $13 \mathrm{~mm}$ of diameter [6]. Papaya contains some specific antimicrobial substrates including carpaine

*Corresponding author: Romana Siddique; E-mail: rsiddique@bracu.ac.bd and aglycons [7]. In the case of the antibacterial assay of dried leaf, green leaf, ripe pulp, ripe peel, root, stem, unripe pulp, unripe peel, and seeds, the maximum zones of inhibition observed are $15 \mathrm{~mm}, 12 \mathrm{~mm}, 12 \mathrm{~mm}, 13 \mathrm{~mm}, 13 \mathrm{~mm}, 28 \mathrm{~mm}, 15 \mathrm{~mm}$, $13 \mathrm{~mm}$, and $14 \mathrm{~mm}$ against $S$. aureus, E. coli, P. aeruginosa, E. coli, P. aeruginosa, S. aureus, $P$. aeruginosa, $S$. aureus, and E. coli, respectively [8]. Citrus fruits have a broad spectrum of biological activity, including antibacterial, antifungal, antidiabetic, anticancer, and antiviral activities due to alkaloids [9]. The acetone extract of Citrus limon used against E. faecalis and Bacillus subtilis gave inhibition zone diameters of 23 and $20 \mathrm{~mm}$, respectively [10]. The methanolic extract of lemon peels exhibited the maximum zone of inhibition $(23 \mathrm{~mm})$ against Pseudomonas aeruginosa [11]. Strawberry is a rich source of folate, vitamin $\mathrm{C}$, several phytochemicals, and phenolic compounds [12]. The $100 \%$ strawberry extract concentration inhibited both monospecies and multispecies E. faecalis and Porphyromonas gingivalis biofilm formation [13]. According to a study, strawberry extracts showed a zone of inhibition of up to $18 \mathrm{~mm}$ against E. coli through the method of agar well diffusion [14]. In the current study, we therefore aim to find out if the commercial fruits available in our country, like green apple, papaya, lemon, and strawberry, have the potency to exhibit antimicrobial activity against bacteria causing urinary tract infection.

\section{Materials and Methods}

Bacterial Strains. The following bacterial strains have been used for the current study: E. coli (ATCC: 15922), E. coli (ATCC: 25922), Klebsiella pneumoniae, Pseudomonas aeruginosa

This is an open-access article distributed under the terms of the Creative Commons Attribution-NonCommercial 4.0 International License (https://creativecommons.org/licenses/by-nc/4.0/), which permits unrestricted use, distribution, and reproduction in any medium for non-commercial purposes, provided the original author and source are credited, a link to the CC License is provided, and changes - if any - are indicated. 


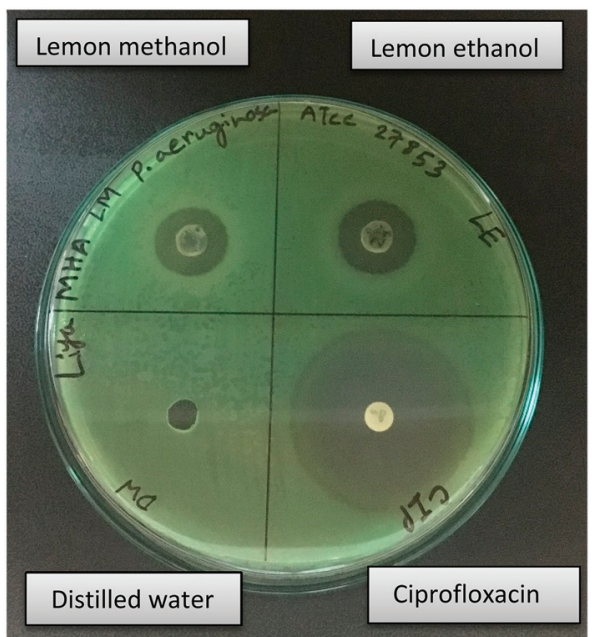

Figure 1. Antimicrobial activity of lemon extracts on $P$. aeruginosa (ATCC: 27853$)(\mathrm{LM}=$ lemon methanol extract; $\mathrm{LE}=$ lemon ethanol extract; $\mathrm{DW}=$ distilled water as negative control; $\mathrm{CIP}=$ ciprofloxacin as positive control)

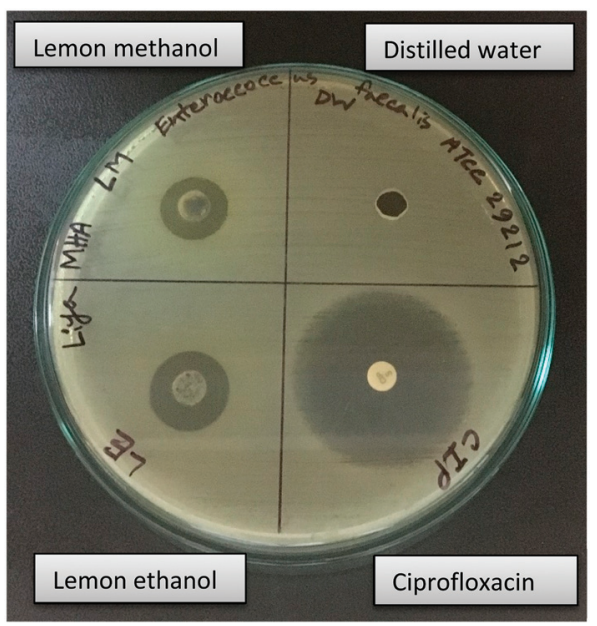

Figure 2. Antimicrobial activity of lemon extracts on E. faecalis (ATCC: 29212$)(\mathrm{LM}=$ lemon methanol extract; $\mathrm{LE}=$ lemon ethanol extract; DW = distilled water as negative control; CIP = ciprofloxacin as positive control)

(ATCC: 27853), and Enterococcus faecalis (ATCC: 29212), which were collected from International Centre for Diarrhoeal Disease Research, Bangladesh (icddr,b). All the bacterial strains were maintained by weekly subculture.

Chemicals and Reagents. The chemicals, agars, and antibiotic discs, which have been used in this experiment, belong to the following companies: Merck (New Jersey, United States),
HiMedia (Mumbai, India) and Oxoid Limited (Cheshire, England), respectively.

Preparation of Fruit Extracts. The fruits were bought fresh from the market and cut into thin slices. Then, they were dried under direct sunlight for 5-6 days and became crispy. Afterwards, they were ground into fine powder by using a grinder. $75 \mathrm{~g}$ of the ground powder was measured and subjected to Soxhlet extraction, where the ground powder is placed in the thimble, and the thimble is put in the chamber of Soxhlet apparatus. The extracting solvent is heated to a boiling point, and the vapors condense in the condenser. The condensed extractant then drips into the thimble containing the powder and extract it by contact. Afterwards, when the liquid reaches a certain level in the siphon tube, the solution containing the extract accumulates in a flask [15]. $250 \mathrm{ml}$ of absolute methanol and absolute ethanol were used as solvents to prepare methanolic and ethanolic crude extracts. Then, the solution was run through a rotary evaporator to evaporate the respective solvents, and the crude extracts were stored in autoclaved Macartney bottles. The crude extracts were later diluted to a concentration of $0.2 \mathrm{mg} / \mu \mathrm{l}$ and $0.6 \mathrm{mg} / \mu \mathrm{l}$ using the same respective solvents before conducting agar well diffusion.

Agar Well Diffusion. The $24 \mathrm{~h}$ subcultured plates of bacterial strains were placed in the laminar hood and were used to make bacterial suspensions. The turbidity of the suspension was compared with the $0.5 \%$ MacFarland standard solution. Then, an autoclaved cotton swab was dipped into the suspension and rubbed horizontally across the surface of the labelled Mueller-Hinton agar (MHA) plates to conduct lawn culture of the bacterial strains. Then, a cork borer was used onto the MHA plates to create 3 wells on 3 different quadrants of the agar. After that, each well was labelled and filled accordingly with $60 \mathrm{~mL}$ of respective diluted methanolic and ethanolic fruit extracts and distilled water. Ciprofloxacin antibiotic disk was used as a positive control and placed onto one quadrant. Then, the MHA plates were kept in the incubator for $24 \mathrm{~h}$ at $37{ }^{\circ} \mathrm{C}$, and the results were recorded the next day. All the tests were conducted 3 times to obtain the mean value of zones of inhibition, which was afterwards used to calculate the standard deviation value for the respective fruit extracts and the activity index for measuring the relative efficacy. The following formula was used to calculate the activity index:

$$
\text { Activity Index }=\frac{\text { Zone of Inhibition of Fruit extract }}{\text { Zone of inhibition of Ciprofloxacin }}
$$

Ethics. This study was performed in accordance to the good laboratory practice (GLP). No ethical approval was needed from the Institutional Review Board because there was no animal involved in conducting the study.

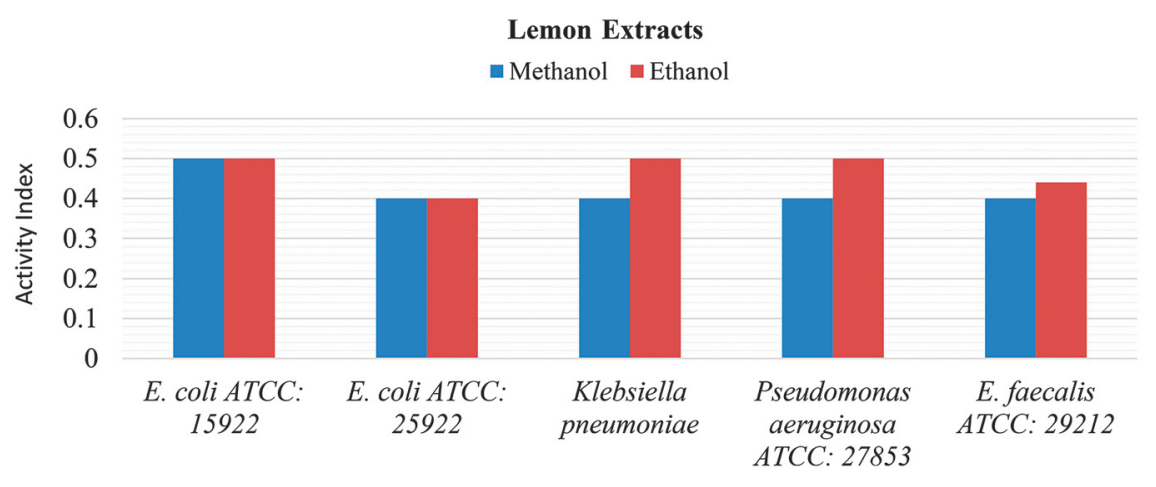

Figure 3. Activity index of lemon methanol and ethanol extracts 


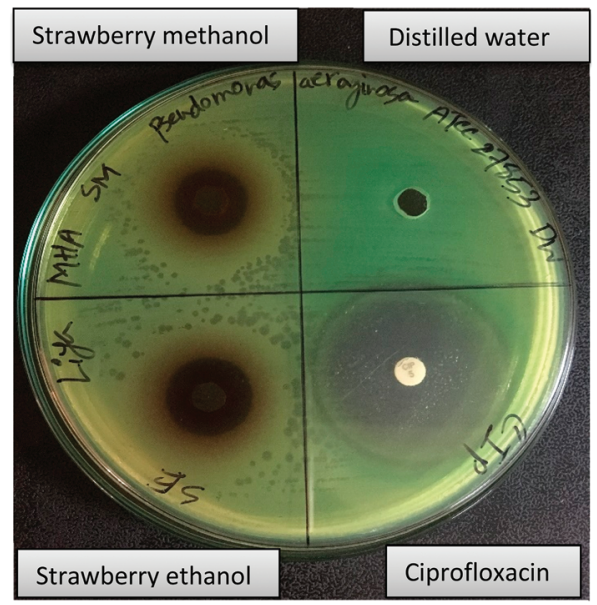

Figure 4. Antimicrobial activity of strawberry extracts on P. aeruginosa (ATCC: 27853$)(\mathrm{SM}=$ strawberry methanol extract; $\mathrm{SE}=$ strawberry ethanol extract; $\mathrm{DW}=$ distilled water as negative control; $\mathrm{CIP}=$ ciprofloxacin as positive control)

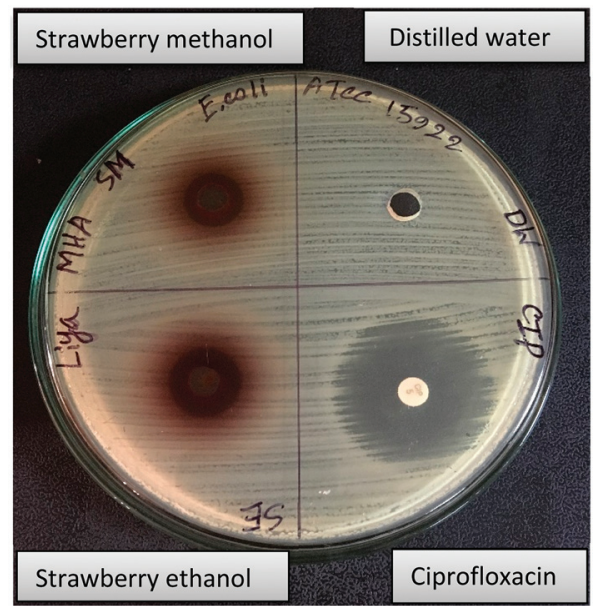

Figure 5. Antimicrobial activity of strawberry extracts on E. coli (ATCC: 15922$)(\mathrm{SM}=$ strawberry methanol extract; $\mathrm{SE}=$ strawberry ethanol extract; DW = distilled water as negative control; CIP = ciprofloxacin as positive control)

\section{Results and Discussion}

Apple. According to this study, apple did not show any zone of inhibition against any of the tested bacteria. Both the ethanol and methanol extracts of apple showed negative results. These findings are surprisingly discordant with several studies conducted earlier using apple extracts. In one study, apple skin extracts were produced through cold maceration technique, using petroleum ether, ethanol and water as the solvents where ethanol extracts of apple gave zone of inhibition against Klebsiella sp. (9.2 mm) and Pseudomonas sp. (16.3 mm) [16]. According another study, both apple methanol and ethanol extracts showed inhibitory activity against $S$. aureus $(14.3 \mathrm{~mm}$ and $13 \mathrm{~mm}$, respectively) and EAEC (16.3 $\mathrm{mm}$ and $14.7 \mathrm{~mm}$, respectively). But the extracts did not show any results against E. faecalis, P. aeruginosa or Klebsiella spp. [17].

The unusual results in the current study may be due to the differences in the variety of apple used in this experiment compared to other studies. Antimicrobial properties are related to the bioactive compounds of the fruits [16], and apples are an important source of bioactive compounds like flavonoids, phenolic compounds, and anti-oxidants. Their concentrations and activity may vary with cultivar and variety [18].

Papaya. In the current study, papaya extracts of methanol and ethanol did not show any zone of inhibition against any of the selected bacteria. According to one study, methanol extracts of Carica papaya leaf showed zone of inhibition against $P$. aeruginosa $(17 \mathrm{~mm})$, E. coli $(12 \mathrm{~mm})$, and Klebsiella pneumoniae (11 mm) [19]. However, the present study was conducted using only the ripened pulp of the papaya fruit, unlike other studies where its leaf or seed or peels were used. In another study, methanolic and ethanolic extracts of ripened papaya fruit pulp were used. The ethanol extract did not give any zone of inhibition for $E$. coli and $P$. aeruginosa. However, the methanol extract showed inhibition zone only against $P$. aeruginosa $(11 \mathrm{~mm})$ but not for $E$. coli [8]. This variance in result may be due to the variety of the papaya used here. Also, the bacterial strains used in the experiments could be more resistant to the inhibitory effects of papaya fruit pulp extracts.

Lemon. The methanolic and ethanolic extracts of lemon showed positive results for all of the bacterial strains tested (Figures 1 and 2). The results were shown as mean value \pm the value of standard deviation. Lemon methanolic extract showed the highest antimicrobial activity against $P$. aeruginosa (ATCC: 27853) $(16.67 \pm 1.53)$ and the lowest antimicrobial activity against $K$. pneumoniae $(14.67 \pm 0.58)$ (Table 1$)$. Lemon ethanolic extract showed the highest antimicrobial activity against $P$. aeruginosa (ATCC: 27853$)(18.34 \pm 0.58)$ and the lowest for $K$. pneumoniae $(16.00 \pm 1.00)$.

In one study, lemon peel was used for ethanolic and methanolic extraction using Soxhlet, which showed antimicrobial activity against E. coli, P. aeruginosa, Klebsiella spp., and Enterococcus spp. (Figure 3). The difference between their study and the current experiment is that they only used the peel, whereas in this study, the whole lemon fruit were used to prepare methanolic and ethanolic crude extract [20]. According to another study, lemon fruit juice extract were made and tested against locally isolated clinical strains of $E$. coli and P. aeruginosa and gave zone of inhibition of $14 \mathrm{~mm}$ and $20 \mathrm{~mm}$, respectively [21]. These

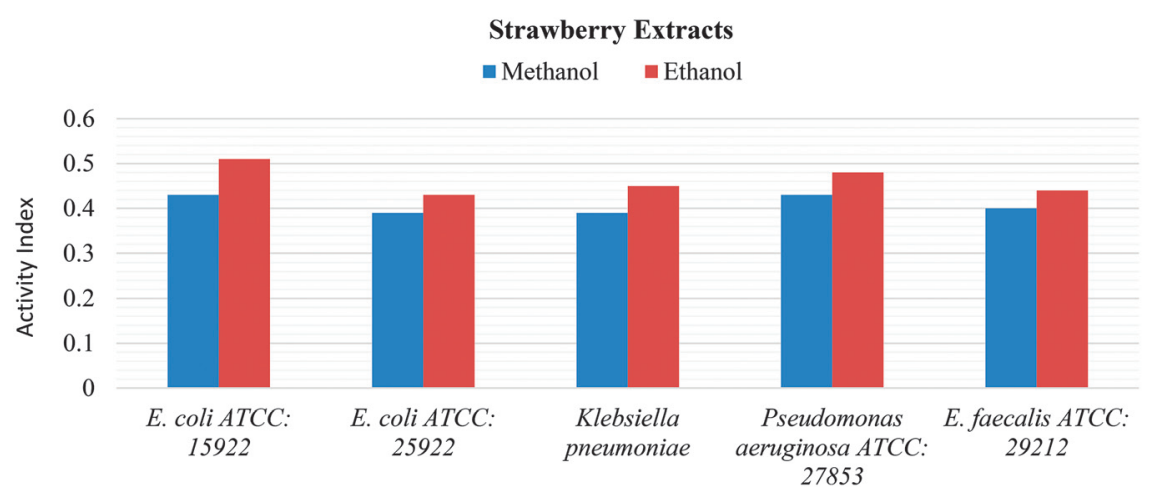

Figure 6. Activity Index of strawberry methanol and ethanol extracts 
Table 1. Antimicrobial test results of lemon extracts $(0.2 \mathrm{mg} / \mu \mathrm{L})$

\begin{tabular}{lcccccc}
\hline Organism & $\begin{array}{c}\text { Mean zone of } \\
\text { inhibition of } \\
\text { ciprofloxacin } \\
(\mathrm{mm})\end{array}$ & $\begin{array}{c}\text { Distilled } \\
\text { water } \\
(\mathrm{mm})\end{array}$ & $\begin{array}{c}\text { Mean zone of } \\
\text { inhibition of } \\
\text { methanol extract } \\
(\mathrm{mm}) \pm \text { standard } \\
\text { deviation value }\end{array}$ & $\begin{array}{c}\text { Activity index } \\
\text { of methanol } \\
\text { extract }\end{array}$ & $\begin{array}{c}\text { Mean zone of } \\
\text { inhibition of } \\
\text { ethanol extract } \\
\text { (mm) } \pm \text { standard } \\
\text { deviation value }\end{array}$ & $\begin{array}{c}\text { Activity index } \\
\text { of ethanol } \\
\text { extract }\end{array}$ \\
\hline E. coli (ATCC: 15922$)$ & $31.67 \pm 1.52$ & 0.00 & $16.34 \pm 0.58$ & 0.5 & $17.32 \pm 0.58$ & 0.5 \\
E. coli (ATCC: 25922) & $32.67 \pm 1.53$ & 0.00 & $15.32 \pm 1.15$ & 0.4 & $16.33 \pm 0.58$ & 0.4 \\
Pseudomonas aeruginosa (ATCC: 27853$)$ & $36.66 \pm 0.58$ & 0.00 & $16.67 \pm 1.53$ & 0.4 & $18.34 \pm 0.58$ & 0.5 \\
E. faecalis (ATCC: 29212) & $37.00 \pm 1.00$ & 0.00 & $16.32 \pm 0.58$ & 0.4 & $17.67 \pm 0.58$ & 0.4 \\
Klebsiella pneumoniae & $30.66 \pm 0.58$ & 0.00 & $14.67 \pm 0.58$ & 0.4 & $16.00 \pm 1.00$ & 0.5 \\
\hline
\end{tabular}

Table 2. Antimicrobial test results of strawberry extract $(0.6 \mathrm{mg} / \mu \mathrm{L})$

\begin{tabular}{lcccccc}
\hline Organism & $\begin{array}{c}\text { Mean zone } \\
\text { of inhibition } \\
\text { of ciprofloxacin } \\
(\mathrm{mm})\end{array}$ & $\begin{array}{c}\text { Distilled } \\
\text { water } \\
(\mathrm{mm})\end{array}$ & $\begin{array}{c}\text { Mean zone of } \\
\text { inhibition of } \\
\text { methanol extract } \\
(\mathrm{mm}) \pm \text { standard } \\
\text { deviation value }\end{array}$ & $\begin{array}{c}\text { Activity index } \\
\text { of methanol } \\
\text { extract }\end{array}$ & $\begin{array}{c}\text { Mean zone of } \\
\text { inhibition of } \\
\text { ethanol extract } \\
\text { (mm) } \pm \text { standard } \\
\text { deviation value }\end{array}$ & $\begin{array}{c}\text { Activity index } \\
\text { of ethanol } \\
\text { extract }\end{array}$ \\
\hline E. coli ATCC: 15922 & $30.00 \pm 1.00$ & 0.00 & $13.00 \pm 1.00$ & 0.43 & $15.33 \pm 0.58$ & 0.51 \\
E. coli ATCC: 25922 & $31.34 \pm 1.53$ & 0.00 & $12.00 \pm 1.00$ & 0.39 & $13.67 \pm 0.58$ & 0.43 \\
Pseudomonas aeruginosa ATCC: 27853 & $34.00 \pm 1.53$ & 0.00 & $14.67 \pm 0.58$ & 0.43 & $16.33 \pm 0.58$ & 0.48 \\
E. faecalis ATCC: 29212 & $32.67 \pm 2.08$ & 0.00 & $13.00 \pm 1.00$ & 0.40 & $14.67 \pm 0.58$ & 0.44 \\
Klebsiella pneumoniae & $29.34 \pm 1.15$ & 0.00 & $11.67 \pm 1.15$ & 0.39 & $13.33 \pm 0.58$ & 0.45 \\
\hline
\end{tabular}

comparisons of studies indicate that lemon holds a good potential as an alternative to commercial antibiotics used nowadays.

Strawberry. The methanolic and ethanolic extracts of strawberry showed positive results for all of the bacterial strains tested (Figures 4-6). The results were shown as mean value \pm the value of standard deviation. Strawberry methanolic extract showed the highest antimicrobial activity against P. aeruginosa (ATCC: 27853) (14.67 \pm 0.58$)$ and lowest antimicrobial activity against $K$. pneumoniae $(11.67 \pm 1.15)$. Ethanolic extract showed highest antimicrobial activity against P. aeruginosa (ATCC: 27853$)(16.33 \pm 0.58)$ and lowest for K. pneumoniae $(13.33 \pm 0.58)$ (Table 2$)$.

Strawberries, which are rich in vitamins and phenolic compounds, have antibacterial and antioxidant effects. The inhibition effect of strawberry extract was studied on monospecies and multispecies $E$. faecalis and $P$. gingivalis bacteria grown as biofilms in vitro. The $100 \%$ strawberry extract concentration inhibited the formation of both the monospecies and multispecies $E$. faecalis and $P$. gingivalis biofilms [13]. In contrast, in another study, strawberry fruit extracts were used to evaluate the antimicrobial activity against certain bacterial and fungal strains by the cup plate diffusion method. Surprisingly, it did not present any antibacterial activity but did show antifungal activity against Candida albicans and Aspergillus niger [22]. Compared to these mixed results of previous experiments, strawberry extracts showed much better results in our study. This difference may be due to the different cultivars of strawberries used in the experiments. The commercially available cultivar of strawberry in our country proves to be a potent antimicrobial agent and therefore holds the potential to be studied and further experimented.

Limitations and Further Scope. Even though the Soxhlet extraction technique is a traditional method for plant material extraction, it does come with a few limitations. To begin with, this technique is very time consuming, and only one solvent can be used for plant extraction at a time, which further delays the time period of the whole experiment. Then, for efficient extraction to occur, Soxhlet extraction requires the plant material to be in the finely ground powdery form, which may not be possible for the fruits, because even after an extensive period of drying the fruits, they still remain a little sticky with a little less surface area.

However, the Soxhlet extraction method is easy to carry out for small scale research regarding plant extraction. For more efficient extraction of the fruits bioactive compounds, other modified extraction methods could also be used. Furthermore, HPLC could be applied to identify and isolate the precise bioactive components of the fruits responsible for antimicrobial activity, so that those components can be further studied to be amplified and be used against the pathogens isolated directly from a UTI patient.

\section{Conclusion}

The use of antibiotics for treating any kind of infection or disease is very common these days. Their use often goes unmonitored or uncontrolled. Such a situation is giving rise to different multi-drug resistant bacteria as well, even in case of UTI. In this scenario, turning to nature is only inevitable, which, considering the advancement in the scientific research field, does not disappoint us. Lemon and strawberry showed antimicrobial potency against the tested bacteria according to this study; hence, looking for the alternatives using fruits is a dependable choice. All we have to do is to choose the right technique for identifying the right component to be used for treating the appropriate infection or disease.

\section{Funding Sources}

No funding was provided by the university or any other agency for carrying out this research work.

\section{Author Contributions}

This work was carried out in collaboration between both authors. R.S. designed the study; S.J.L. managed the sample collection and laboratory analyses. R.S. and S.J.L. managed the literature searches, performed the statistical analysis, wrote the protocol, and wrote the first draft of the manuscript. Both authors read and approved the final manuscript.

\section{Conflict of Interest}

There is no conflict of interest among the authors.

\section{References}

1. Mishra MP, Rath S, Swain SS, Ghosh G, Das D, Padhy RN. In vitro antibacterial activity of crude extracts of 9 selected medicinal plants against UTI causing MDR bacteria. J King Saud Univ Sci. 2017;29:84-95.

2. Flores-Mireles AL, Walker JN, Caparon M, Hultgren SJ. Urinary tract infections: epidemiology, mechanisms of infection and treatment options. Nat Rev Microbiol. 2015;13:269-84. 
3. Foxman B. The epidemiology of urinary tract infection. Nat Rev Urol. 2010;7:653-60.

4. Sharma A, Chandraker S, Patel VK, Ramteke P. Antibacterial Activity of Medicinal Plants against Pathogens causing Complicated Urinary Tract Infections. Indian J Pharm Sci. 2009;71:136-9.

5. Boyer J, Liu RH. Apple phytochemicals and their health benefits. Nutr J. 2004;3:1-45.

6. Fratianni F, Sada A, Cipriano L, Masucci A, Nazzaro F. Biochemical Characteristics, Antimicrobial and Mutagenic Activity in Organically and Conventionally Produced Malus domestica, Annurca, Open Food Sci J. 2007;1:10-6.

7. Bansode DS, Chavan MD. Evaluation of antimicrobial activity and phytochemical analysis of papaya and pineapple fruit juices against selected enteric pathogens. Int J Pharm Bio Sci. 2013;4:1176-84.

8. Khan JA, Yadav JS, Srivastava Y, Pal PK. In vitro evaluation of antimicrobial properties of Carica papaya. Int J Biol Pharm Allied Sci. 2012;1:933-45.

9. Ali J, Das B, Saikia T. Antimicrobial Activity of Lemon Peel (Citrus limon) Extract. Int J Curr Pharm Res. 2017;9:268-73.

10. Otang WM, Afolayan AJ. Antimicrobial and antioxidant efficacy of Citrus limon L. peel extracts used for skin diseases by Xhosa tribe of Amathole District, Eastern Cape, South Africa. S Afr J Bot. 2016;102: 46-9.

11. Pandey A, Kaushik A, Tiwari SK. Evaluation of Antimicrobial Activity and Phytochemical Analysis of Citrus limon. J Pharm Biomed Sci. 2011;13:1-7.

12. Amatori S, Mazzoni L, Alvarez-Suarez JM, Giampieri F, Gasparrini M, Forbes-Hernandez TY, et al. Polyphenol-rich strawberry extract (PRSE) shows in vitro and in vivo biological activity against invasive breast cancer cells. Sci Rep. 2016;6:1-13.
13. Widyarman AS, Widjaja SB, Idrus E. Strawberry Extract's Effects on Enterococcus faecalis and Porphyromonas gingivalis Biofilms in vitro. Sci Dent J. 2017:1:1-5.

14. Puupponen-Pimia R, Nohynek L, Meier C, Kahkonen M, Heinonen M, Hopia A, et al. Antimicrobial properties of phenolic compounds from berries. J Appl Microbiol. 2001;90:494-507.

15. Handa SS, Khanuja SPS, Longo G, Rakesh DD. Extraction Technologies for Medicinal and Aromatic Plants. 1st ed. Trieste:ICS-UNIDO; 2008.

16. Sunilson JAJ, Kumari AVAG, Khan A, Anandarajagopal K. Effects of Malus domestica Fruit Extracts Against Clinically Isolated Dental Pathogens. Eur J Dent Med. 2016;8:12-6.

17. Kabir S, Jahan SM, Hossain MM, Siddique R. Apple, Guava and Pineapple Fruit Extracts as Antimicrobial Agents against Pathogenic Bacteria. Am J Microbiol Res. 2017;5:101-6.

18. Gonzalez-Aguilar G, Robles-Sanchez RM, Martinez-Tellez MA, Olivas GI, Alvarez-Parrilla E, De La Rosa LA. Bioactive compounds in fruits: Health benefits and effect of storage conditions. Stewart Postharvest Review. 2008;4:1-10.

19. Aruljothi S, Uma C, Sivagurunathan P, Bhuvaneswari M. Investigation on Antibacterial Activity of Carica papaya Leaf Extracts against Wound Infection-Causing Bacteria. Int J Res Stud Bio Sci. 2014;2:8-12.

20. Tumane PM, Meshram VG, Wasnik DD. Comparative study of antibacterial activity of peel extracts of Citrus aurantium L. (Bitter Orange) and Citrus medica L. (Lemon) against clinical isolates from wound infection. Int J Pharma Bio Sci. 2014;5:382-7.

21. Okeke MI, Okoli AS, Eze EN, Ekwume GC, Okosa EU, Iroegbu CU. Antibacterial activity of Citrus limonum fruit juice extract. Pak J Pharm Sci. 2015;28:1567-71.

22. Debnath S, Rahman H, Deshmukh G, Duganath N, Pranitha C, Chiranjeevi A. Antimicrobial Screening of Various Fruit Seed Extracts. Pharmacogn J. 2011;3:83-6. 